\title{
Preventive effect of hesperidin modulates inflammatory responses and antioxidant status following acute myocardial infarction through the expression of PPAR- $\gamma$ and Bcl-2 in model mice
}

\author{
CHUNYING MENG ${ }^{1}$, ZEHENG GUO ${ }^{2}$, DAGANG LI ${ }^{1}$, HANWEI LI $^{1}$, JIANBIN HE ${ }^{1}$, DINGGUO WEN ${ }^{1}$ and BIN LUO ${ }^{1}$ \\ ${ }^{1}$ Department of Thoracic and Cardiovascular Surgery, Jinan University 2nd Clinical Medicine \\ College, Shenzhen People's Hospital, Shenzhen, Guangdong 518020; ${ }^{2}$ Futian District Maternal \\ and Child Health Hospital of Shenzhen, Shenzhen, Guangdong 518045, P.R. China
}

Received August 22, 2016; Accepted July 13, 2017

DOI: $10.3892 / \mathrm{mmr} .2017 .7981$

\begin{abstract}
Hesperetin is the main pharmacological ingredient of fruit of the citrus family, rutaceae. It is a flavanone, which has potent antioxidation and anti-inflammatory activities. The present study investigated the preventive effect of hesperidin in the modulation of acute myocardial infarction (AMI)-induced inflammatory responses and antioxidant status in a mouse model. The levels of creatine kinase-MB, tumor necrosis factor (TNF- $\alpha$ ), interleukin (IL)-1 $\beta$, IL-6, monocyte chemoattractant protein 1 (MCP-1), intercellular adhesion molecule 1 (ICAM-1), malondialdehyde (MDA), catalase (CAT), superoxide dismutase (SOD) and caspase-3/9 were measured using ELISA kits. Western blot analysis analyzed p53 and B-cell lymphoma 2 (Bcl-2)-associated X protein/Bcl-2, and induced the expression of peroxisome proliferator-activated receptor- $\gamma$ $($ PPAR- $\gamma)$. Hesperidin markedly decreased the myocardial infarction area, heart weight/body weight ratio and activity of creatine kinase-MB in AMI mice. Hesperidin treatment caused a significant decrease in the levels of TNF- $\alpha$, IL-1 $\beta$, IL-6, MCP-1, ICAM-1, MDA, CAT, SOD and caspase-3/9 in mice with AMI. Hesperidin also significantly suppressed the protein expression levels of p53 and $\mathrm{Bax} / \mathrm{Bcl}-2$, and induced the expression of peroxisome proliferator-activated receptor- $\gamma($ PPAR- $\gamma)$ in mice with AMI. The preventive effect of hesperidin modulated the inflammatory response and antioxidant status following AMI through downregulation of the expression of PPAR- $\gamma$ and Bcl- 2 in the model mice.
\end{abstract}

\footnotetext{
Correspondence to: Dr Zeheng Guo, Futian District Maternal and Child Health Hospital of Shenzhen, 2002 Jintian Road, Futian, Shenzhen, Guangdong 518045, P.R. China

E-mail: guozeheng8900@163.com
}

Key words: hesperidin, acute myocardial infarction, peroxisome proliferator-activated receptor- $\gamma$, B-cell lymphoma 2

\section{Introduction}

Acute myocardial infarction (AMI) is a disease, which seriously endangers human health. A large number of myocardial cells in the infarcted region are lost due to ischemia and hypoxia (1). As the numbers of myocardial cells decrease, cardiac function is subjected to a progressive decrease in the ventricular remodeling process. This is due to the necrotic cardiac muscle tissue being unable to recover, and being substituted only by collapsed scar tissue without contraction function (2). At present, the therapeutic methods for AMI mainly include drug therapy, interventional therapy and surgery, which can only improve the damaged myocardium and reduced myocardial function following ischemia, even with recovery in blood flow (3). However, these types of therapy do not recover the functions of necrotic myocardium. With the process of ventricular remodeling, this eventually leads to heart failure and a decrease in patient quality of life (4). The clinical symptoms and prognosis of patients can be improved by the use of drugs, a ventricular assist device and heart transplantation. However, studies have shown that, following a diagnosis of congestive heart failure, $20 \%$ of patients succumb to mortality within 1 year (1).

AMI is a pathological process accompanied by an inflammatory response. Inflammatory cytokines are important in ventricular remodeling following myocardial infarction (5). At the early stage of infarction, the local inflammatory reaction is prominent and, with high levels of inflammatory cell infiltration, inflammatory cells and inflammatory cytokine can adversely affect cell-transplant therapy (6).

Oxidative stress refers to the pathological process of excessive oxygen and/or a reduction in antioxidation ability, and disturbance in the balance between the oxidation system and antioxidant system generated by reactive oxygen leads to latent injury (7). In previous years, a number of studies have shown that oxidative stress is an essential mechanism for the genesis and development of cardiovascular disease (8).

Peroxisome proliferator-activated receptor (PPAR) is a ligand-activated transcription factor. It belongs to the nuclear receptor super-family (9). PPARs are divided into three sub-types, namely PPAR $\alpha, \operatorname{PPAR} \beta$ and PPAR- $\gamma(10)$. 
Studies have shown that PPARs can inhibit the inflammatory response in vitro and in vivo $(10,11)$. PPAR- $\gamma$ is expressed in endothelial cells of the aorta and carotid artery, and in umbilical vein endothelial cells. Its ligand can inhibit the expression of intercellular adhesion molecule 1 (ICAM-1) induced by cytokines (11). PPAR- $\gamma$ is also expressed in human vascular endothelial cells, vascular smooth muscle cells and mononuclear macrophages. PPAR- $\gamma$ ligands can prevent the accumulation of inflammatory cells through inhibiting the expression of interleukin (IL)-8, monocyte chemoattractant protein 1 (MCP-1) and ICAM-1 $(9,12)$.

Studies have shown that the content of apoptotic factors in infarcted mice myocardial cells can be inhibited through drug pretreatment, including the expression of P53, B-cell lymphoma 2 ( $\mathrm{Bcl}-2$ )-associated $\mathrm{X}$ protein $(\mathrm{Bax})$ and Fas $(13,14)$. Results have shown that, in cases showing an effective increase in the expression of Bcl-2, cell apoptosis was markedly decreased. Cytochrome $c$ forms apoptotic bodies following release, and has effects on caspase-9 protein composition (15). Cell apoptosis is eventually induced through activating downstream caspase- 3 and other cells (15). This indicates that decreasing the activity or reducing the expression levels of caspase-3 and caspase-9 protease can effectively inhibit myocardial cell apoptosis (16). The Bcl-2 family can regulate the release of cytochrome $c$ in the mitochondria. Therefore, the activation of apoptotic cytochrome $c$ can be inhibited to inhibit the genesis of cell apoptosis (15).

Hesperetin is the main pharmacological ingredient of the fruit of the citrus family, rutaceae. It is flavanone, which is originates mainly from the hydrolysate of hesperidin. The glucoside can generate hesperetin from hydrolyzation, and function in the human intestinal flora. It is enriched in pericarpium citri reticulatae viride, pericarpium citri reticulatae and immature bitter orange. Its pharmacologic actions include stomach, phlegm removal, cough and cold relief, diuretic, antiviral and antibiotic effects and stomach pain relief. Studies have shown hesperetin has potent effects against oxidative stress, inflammation and allergy. The present study investigated the preventive effect of hesperidin in the modulation of AMI-induced inflammatory responses and antioxidant status.

\section{Materials and methods}

Animals and treatment. Experiments were performed in accordance with the animal ethics guidelines of the Institutional Animal Ethics Committee of Jinan University 2nd Clinical Medicine College (Shenzhen, China). C57BL/6 male mice (18-20 g; 5-6 weeks old) were purchased from Shenzhen Advanced Animal Study Service Center (Shenzhen, China) and housed in sterilized polypropylene rat cages, under a $12 / 12$-h light/dark cycle, at an ambient temperature of $22-23^{\circ} \mathrm{C}$ and ambient humidity of 55-60\%, under specific-pathogen-free conditions.

The mice were randomly divided into four equal groups, each containing eight mice: Control group, AMI group, $50 \mathrm{mg} / \mathrm{kg} / \mathrm{d}$ histamine group and $100 \mathrm{mg} / \mathrm{kg} / \mathrm{d}$ histamine group. Anesthesia was performed by inhalation of 1.0-2.0\% isoflurane gas. A left thoracotomy was performed to expose the heart, and myocardial infarction was induced and ligated using an 8-0 silk suture at the left anterior descending coronary artery. Following closure of the chest wall, the mice were extubated. The mice were administered orally with PBS, 50 or $100 \mathrm{mg} / \mathrm{kg}$ of histamine for 2 weeks in the AMI group, $50 \mathrm{mg} / \mathrm{kg} / \mathrm{d}$ histamine group and $100 \mathrm{mg} / \mathrm{kg} / \mathrm{d}$ histamine group, respectively. Following treatment with histamine, the animals were sacrificed under $1.0-2.0 \%$ isoflurane gas. The body weights and heart weights were recorded, and were stored at $-80^{\circ} \mathrm{C}$ until analysis.

Measurement of infarct size. Following histamine administration and sacrifice of the animals under 1.0-2.0\% isoflurane gas, the hearts were removed and weighed, and sliced into 4.0-mm thick sections perpendicularly. The sections were then incubated with $1 \%$ triphenyltetrazolium chloride (Sigma; Merck Millipore; Darmstadt, Germany) in phosphate solution for $10 \mathrm{~min}$ at $37^{\circ} \mathrm{C}$. Infarct size was determined by computer morphometry using Image-Pro Plus 6.0 software (Media Cybernetics, Inc., Rockville, MD, USA).

Biochemical assay. Following histamine treatment, serum samples from the mice were collected after centrifugation $\left(2,000 \mathrm{xg}\right.$ for $10 \mathrm{~min}$ at $\left.4^{\circ} \mathrm{C}\right)$ to determine the levels of creatine kinase (CK)-MB, tumor necrosis factor (TNF- $\alpha$ ), IL-1 $\beta$, IL-6, MCP-1, ICAM-1, malondialdehyde (MDA), catalase (CAT), superoxide dismutase (SOD) and caspase-3/9 using ELISA kits.

Western blot analysis. Following histamine treatment, the hearts were removed and homogenized in cytoplasmic and protease inhibitors (Thermo Fisher Scientific, Inc., Waltham, MA, USA). The lysates were centrifuged at $12,000 \mathrm{xg}$ for $10 \mathrm{~min}$ at $4^{\circ} \mathrm{C}$ to analyze protein concentrations using a BCA assay (Beyotime Institute of Biotechnology, Haimen, China). Total protein $(50 \mu \mathrm{g})$ was resolved by SDS-PAGE (6-10\%) and the samples were blocked with 5\% non-milk fat in TBST for $1 \mathrm{~h}$ at $37^{\circ} \mathrm{C}$ and immunoblotted with p53 (catalog no. 2524; 1:2,000; Cell Signaling Technology, Inc., Danvers, MA, USA), Bax (catalog no. 14796; 1:2,000, Cell Signaling Technology, Inc.), Bcl-2 (catalog no. 3498; 1:2,000, Cell Signaling Technology, Inc.), PPAR- $\gamma$ (catalog no. 2435; 1:2,000; Cell Signaling Technology, Inc.) and GAPDH (cat. no. AF0006; 1:2,000; Beyotime Institute of Biotechnology) following transfer onto polyvinylidene difluoride membranes at $4^{\circ} \mathrm{C}$ overnight. Following washing, the membranes were incubated with secondary antibodies conjugated to horseradish peroxidase (cat. no. A0208; 1:5,000; Beyotime Institute of Biotechnology) for $1 \mathrm{~h}$ at $37^{\circ} \mathrm{C}$, and the bands were developed with ECL Plus Western blot detection reagents (GE Healthcare Life Sciences, Chalfont, UK).

Statistical analysis. All values are presented as the mean \pm standard deviation using SPSS software version 17.0 (SPSS, Inc., Chicago, IL, USA). Comparisons between two groups were assessed using Student's $t$ test or two-way analysis of variance followed by Bonferroni's post hoc test. $\mathrm{P}<0.05$ was considered to indicate a statistically significant difference.

\section{Results}

Preventive effect of hesperidin on infarct size of AMI mice. The constitutional formula of hesperidin is shown in Fig. 1. The present study investigated the preventive effect of 
hesperidin on infarct size in AMI mice. A significant increase in infarct size was found in the AMI mice, compared with that in the control group (Fig. 2). Treatment with 50 and $100 \mathrm{mg} / \mathrm{kg}$ hesperidin significantly inhibited infarct size in the AMI mice, compared with AMI model group (Fig. 2).

Preventive effect of hesperidin on heart weight/body weight ratio and activity of creatine kinase $(C K-M B)$ in AMI mice. The present study analyzed whether the preventive effect of hesperidin affected the heart weight/body weight ratio and activity of CK-MB in AMI mice. Compared with the control group, there were significant increases in the heart weight/body weight ratio and activity of CK-MB in the AMI mice (Fig. 3A and B). However, treatment with 50 and $100 \mathrm{mg} / \mathrm{kg}$ hesperidin significantly inhibited the heart weight/body weight ratio and the activity of CK-MB in the AMI mice, compared with the AMI model group (Fig. 3A and B).

Preventive effect of hesperidin on inflammatory responses in AMI mice. The present study examined the anti-inflammatory effect of hesperidin in AMI mice. The activities of TNF- $\alpha$, IL- $1 \beta$ and IL- 6 were analyzed using ELISA kits. In the AMI mice, significant increases in the activities of TNF- $\alpha$, IL-1 $\beta$ and IL- 6 were found, compared with those in the control group (Fig. 4A-C). The increases in the activities of TNF- $\alpha$, IL-1 $\beta$ and IL- 6 were significantly prevented by treatment with 50 and $100 \mathrm{mg} / \mathrm{kg}$ hesperidin in the AMI mice, compared with activities in the AMI model group (Fig. 4A-C).

Preventive effect of hesperidin on the expression of $M C P-1$ and ICAM-1 in AMI mice. In order to identify the anti-inflammatory effect of hesperidin in AMI mice, the activity of MCP-1 and protein expression of ICAM-1 were analyzed. Similar to the other findings in the mice, the activity of MCP-1 and the protein expression of ICAM-1 were higher in the AMI mice, compared with those in the control group (Fig. 5A-C). Treatments with 50 and $100 \mathrm{mg} / \mathrm{kg}$ hesperidin significantly suppressed the MCP-1 level and protein expression of ICAM-1 in the AMI mice, compared with those in the AMI model group (Fig. 5A-C).

Preventive effect of hesperidin on the antioxidant status of AMI mice. To investigate the antioxidant effect of hesperidin on AMI mice, the activities of MDA, SOD and CAT were analyzed using ELISA assays. The activity of MDA was increased, and the activities of SOD and CAT were reduced in the AMI mice, compared with those in the control group (Fig. 6A-C). Treatment with 50 and $100 \mathrm{mg} / \mathrm{kg}$ hesperidin significantly inhibited the activity of MDA, and promoted the activities of SOD and CAT in AMI mice, compared with the AMI model group (Fig. 6A-C).

Preventive effect of hesperidin on caspase-3 and caspase-9 of AMI mice. To evaluate the preventive effect of hesperidin on cardiomyocyte apoptosis in AMI mice, the activities of caspase- 3 and caspase-9 were measured using an ELISA assay. The results of the ELISA assay revealed that the activities of caspase- 3 and caspase-9 in the AMI mice were higher, compared with those in the control group mice (Fig. 7). Treatment with 50 and $100 \mathrm{mg} / \mathrm{kg}$ hesperidin significantly reduced the activities of caspase- 3 and caspase- 9 in the

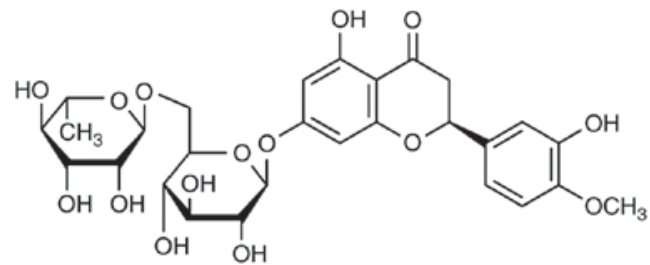

Figure 1. Constitutional formula of hesperidin.

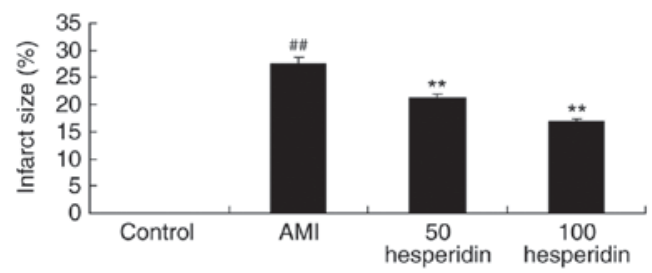

Figure 2. Preventive effect of hesperidin on infarct size in AMI mice. ${ }^{\# \#} \mathrm{P}<0.01$, compared with the control group; ${ }^{* *} \mathrm{P}<0.01$, compared with AMI model mice group. AMI, acute myocardial infarction; Control, control group; 50 hesperidin, $50 \mathrm{mg} / \mathrm{kg}$ hesperidin-treated group; 100 hesperidin, $100 \mathrm{mg} / \mathrm{kg}$ hesperidin-treated group.

AMI mice, compared with those in the AMI model group mice (Fig. 7).

Preventive effect of hesperidin on the protein expression of p53 in AMI mice. To clarify the preventive effect of hesperidin on the mechanism of cardiomyocyte apoptosis in AMI mice, the protein expression of p53 was measured using western blot analysis. A significant increase in the protein expression of p53 was observed in the AMI mice, compared with that in the control group mice (Fig. 8A and B). Treatment with hesperidin (50 and $100 \mathrm{mg} / \mathrm{kg}$ ) significantly suppressed the protein expression of p53 in the AMI mice, compared with that in the AMI model group mice (Fig. 8A and B).

Preventive effect of hesperidin on the protein expression of Bax/Bcl-2 in AMI mice. To further clarify the preventive effect of hesperidin on the mechanism of cardiomyocyte apoptosis of AMI mice, the protein expression of Bax/Bcl-2 in AMI mice was measured using a western blot analysis. The protein expression of $\mathrm{Bax} / \mathrm{Bcl}-2$ in the AMI mice was significantly increased, compared with that in the control group. Administration with 50 and $100 \mathrm{mg} / \mathrm{kg}$ of hesperidin significantly inhibited the protein expression of Bax/Bcl-2 in the AMI mice, compared with that in the AMI model group mice (Fig. 9A and B).

Preventive effect of hesperidin on the protein expression of $P P A R-\gamma$ in AMI mice. To examine the preventive effect of hesperidin in AMI, the protein expression of PPAR- $\gamma$ was analyzed in AMI mice treated with hesperidin. The protein expression of PPAR $-\gamma$ was significantly suppressed in the AMI mice, compared with the control group mice (Fig. 10A and B). Treatment with 50 and $100 \mathrm{mg} / \mathrm{kg}$ of hesperidin significantly increased the protein expression of PPAR- $\gamma$ in the AMI mice, compared with that in the AMI model group mice (Fig. 10A and B). 

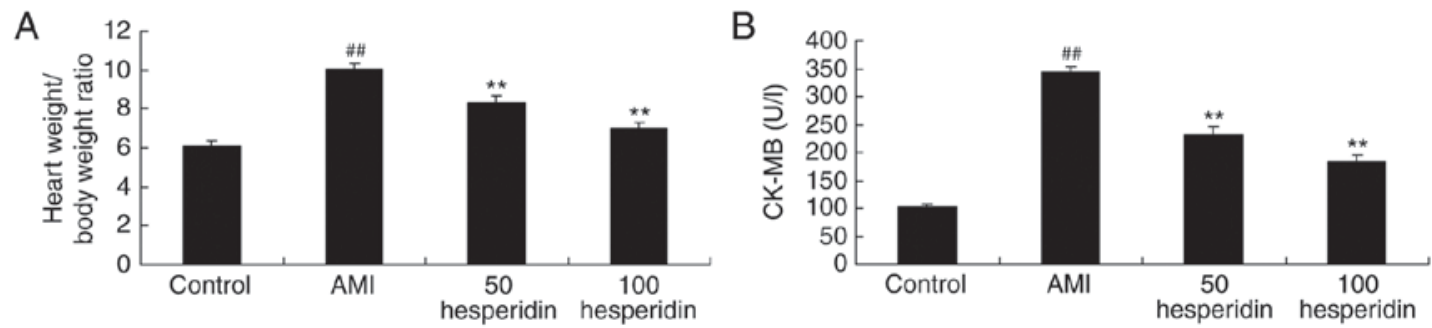

Figure 3. Preventive effect of hesperidin on heart weight/body weight ratio and the activity of CK-MB in AMI mice. Preventive effect of hesperidin on (A) heart weight/body weight ratio and the (B) activity of CK-MB in AMI mice. ${ }^{\# \#} \mathrm{P}<0.01$, compared with control group; ${ }^{* *} \mathrm{P}<0.01$, compared with AMI model mice group. AMI, acute myocardial infarction; Control, control group; 50 hesperidin, $50 \mathrm{mg} / \mathrm{kg}$ hesperidin-treated group; $100 \mathrm{hesperidin}, 100 \mathrm{mg} / \mathrm{kg}$ hesperidin-treated group; CK-MB, creatine kinase-MB.
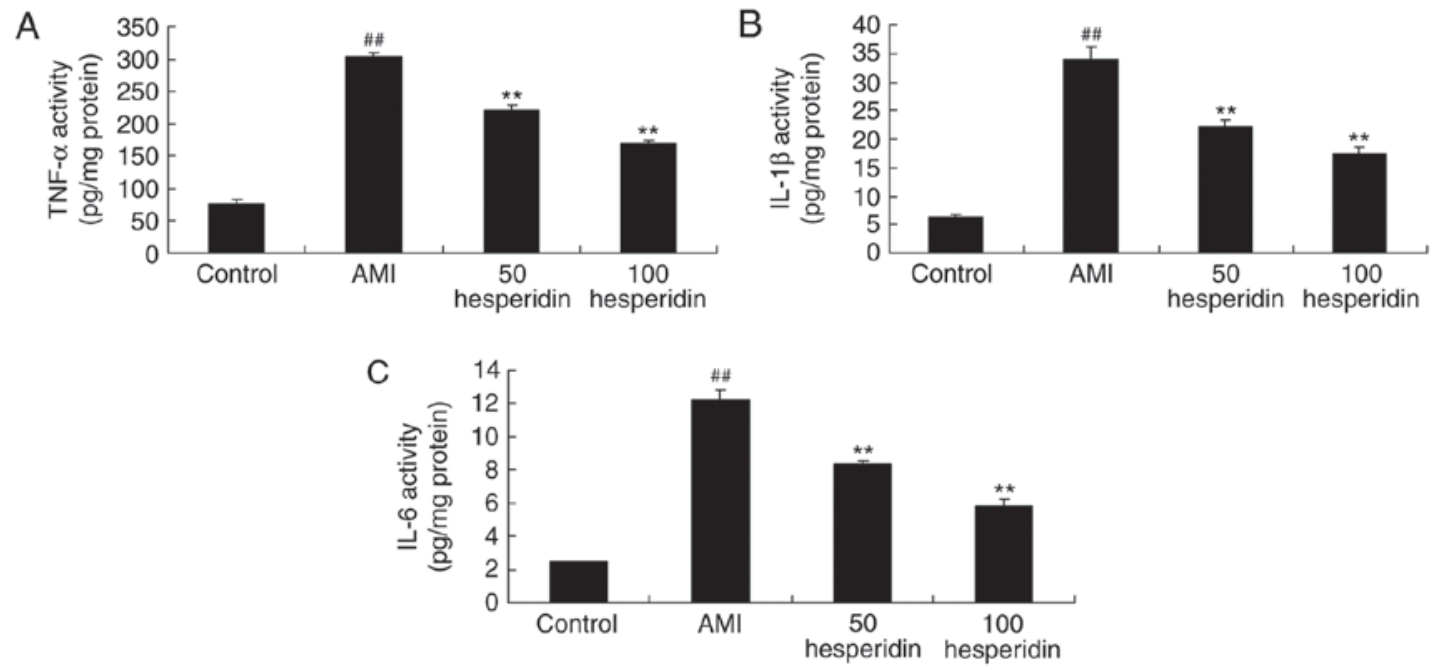

Figure 4. Preventive effect of hesperidin on inflammatory responses of AMI mice. Preventive effect of hesperidin on the activities of (A) TNF- $\alpha$, (B) IL-1 $\beta$ and (C) IL-6 in AMI mice. ${ }^{\# \#} \mathrm{P}<0.01$, compared with control group; ${ }^{* * *} \mathrm{P}<0.01$, compared with AMI model mice group. AMI, acute myocardial infarction; Control, control group; 50 hesperidin, $50 \mathrm{mg} / \mathrm{kg}$ hesperidin-treated group; 100 hesperidin, $100 \mathrm{mg} / \mathrm{kg}$ hesperidin-treated group; TNF- $\alpha$, tumor necrosis factor- $\alpha$, IL, interleukin.

\section{Discussion}

In the majority of developed countries, AMI is the primary contributor to human mortality rates. AMI therapy, including early reperfusion, reduces the mortality rates of patients with AMI substantially (17). However, left ventricular remodeling and heart failure have become important health concerns. At present, the therapeutic methods for cardiac remodeling following myocardial infarction are limited (18). Consequently, the identification of key targets and therapeutic methods for poor left ventricular remodeling has become a priority. The results from the present study showed that hesperidin significantly inhibited the infarct size, heart weight/body weight ratio and activity of CK-MB in AMI mice.

The inflammatory reaction is a complex dynamic pathological process caused by tissue damage and infection (19). Typical inflammatory responses can lead to vasodilation, increased blood flow, increased vascular permeability through the release of a series of inflammatory factors (20). AMI is the process of myocardial ischemic necrosis caused by acute coronary artery occlusion, and is accompanied by tissue necrosis and inflammatory reaction (21). Studies have shown that several inflammatory mediums are involved in the pathological process of AMI, including increases in TNF- $\alpha$, IL-1 $\beta$, IL6, prostaglandin and leukotrienes $(20,22)$. In acute inflammatory reactions, multinuclear leukocyte accumulation and infiltration, and increased reactive protein generation are observed (21). However, severe inflammation caused by AMI is detrimental to the survival of transplanted cells. The release of a large quantity of acute inflammatory medium aggravates ischemia reperfusion injury of the myocardium, and affects the survival and function of the transplanted cells (23). The results of the present study indicated that 50 and $100 \mathrm{mg} / \mathrm{kg}$ hesperidin significantly prevented the increases in the activities of TNF- $\alpha$, IL-1 $\beta$ and IL-6, activity of MCP-1 and protein expression of ICAM-1 in the AMI mice. Rotimi et al reported that hesperidin also prevents lipopolysaccharide-induced oxidative stress and inflammation in rats (24).

Oxidative stress refers to damage of the oxidant/antioxidant equilibrium. Oxidative stress is a common characteristic of diabetes and hypertension. During the process of ischemia reperfusion injury, $\mathrm{H}_{2} \mathrm{~S}$ can inhibit the generation of myocardial cell mitochondrial cytochrome $c$ oxidase, reduce the generation of $\mathrm{O}_{2}^{-}$, and protect the structure and functions of mitochondria (25). Oxidative stress, intracellular ionized calcium overload and mitochondrial dysfunction are essential 


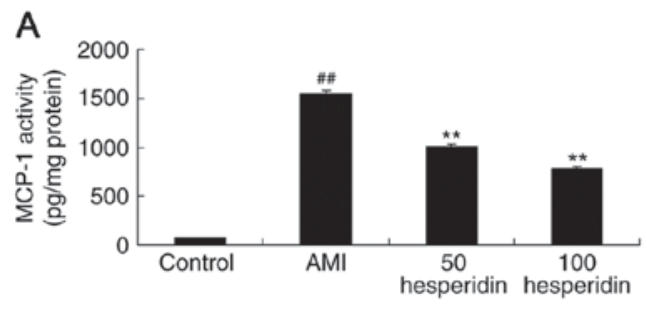

B

C
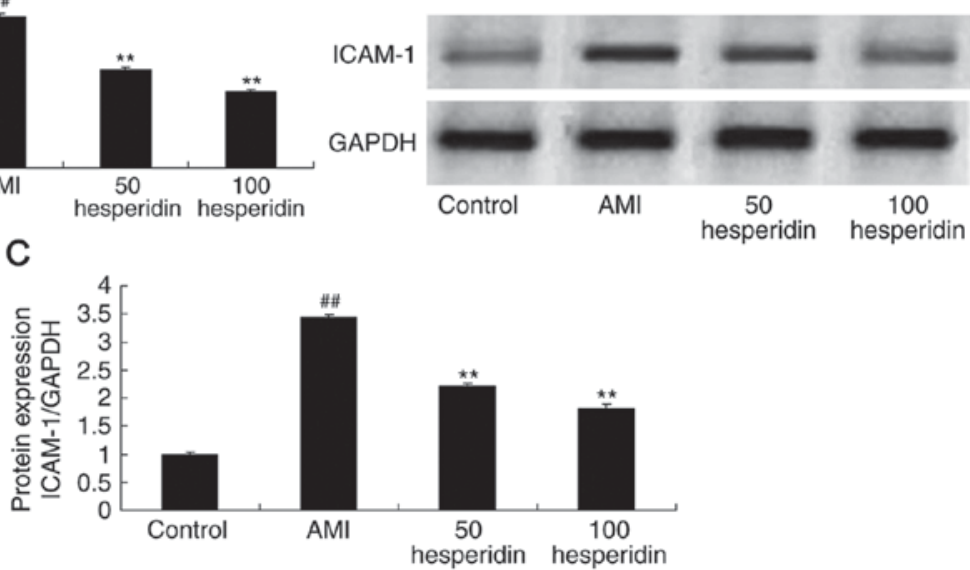

Figure 5. Preventive effect of hesperidin on MCP-1 and ICAM-1 in AMI mice. Preventive effect of hesperidin on the protein expression of (A) MCP-1 and (B and C) ICAM-1, determined using statistical analysis. ${ }^{\# \#} \mathrm{P}<0.01$, compared with control group; ${ }^{* * *} \mathrm{P}<0.01$, compared with AMI model mice group. AMI, acute myocardial infarction; Control, control group; 50 hesperidin, $50 \mathrm{mg} / \mathrm{kg}$ hesperidin-treated group; 100 hesperidin, $100 \mathrm{mg} / \mathrm{kg}$ hesperidin-treated group; MCP-1, monocyte chemoattractant protein 1; ICAM-1, intercellular adhesion molecule 1.
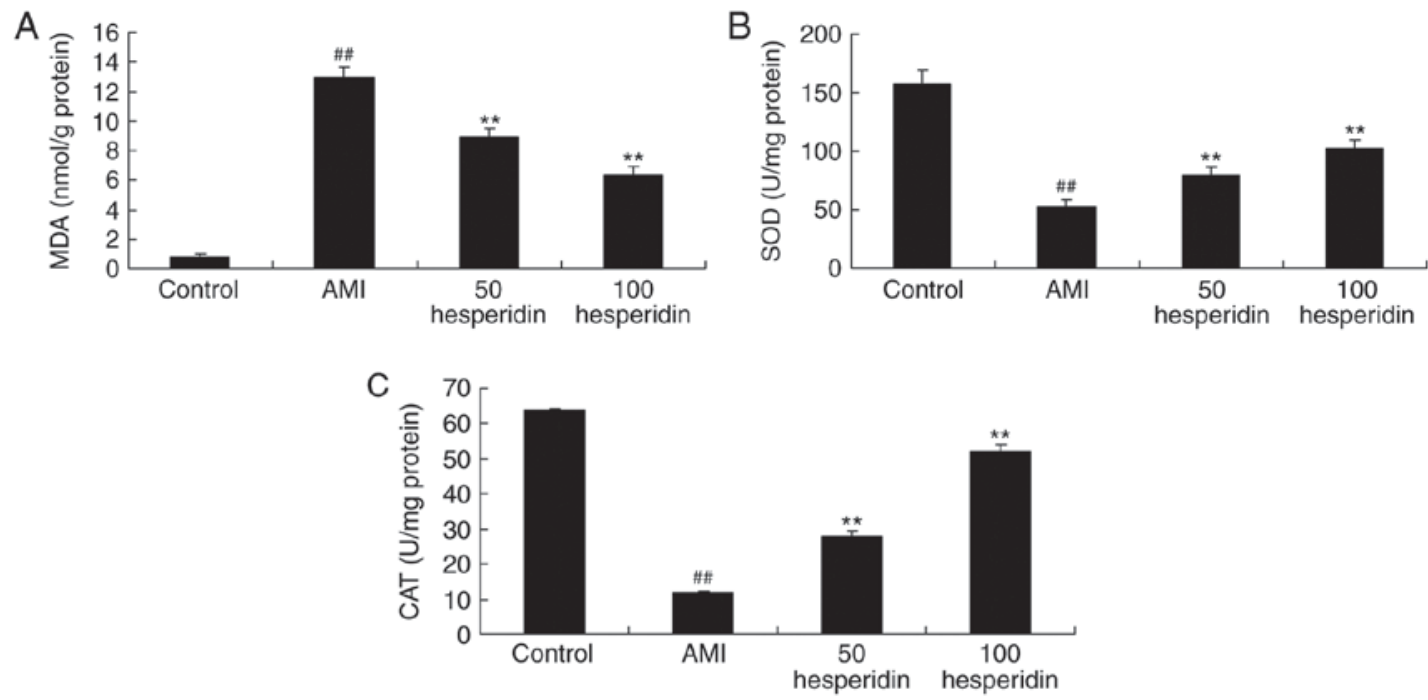

Figure 6. Preventive effect of hesperidin on the antioxidant status of AMI mice. Preventive effect of hesperidin on activities of (A) MDA, (B) SOD and (C) CAT in AMI mice. ${ }^{\# \#} \mathrm{P}<0.01$, compared with control group; ${ }^{* *} \mathrm{P}<0.01$, compared with AMI model mice group. AMI, acute myocardial infarction; Control, control group; 50 hesperidin, $50 \mathrm{mg} / \mathrm{kg}$ hesperidin-treated group; 100 hesperidin, $100 \mathrm{mg} / \mathrm{kg}$ hesperidin-treated group; MDA, malondialdehyde; SOD, superoxide dismutase; CAT, catalase.

factors leading to myocardial cell apoptosis (12). Oxidative stress is a factor, which has been of particular concern. In myocardial infarction and other pathological states, the generation of oxygen ions under a reduction state, namely reactive oxygen species (ROS), exceeds the unsteady state of cell endogenous detoxification and/or utilization capability (7). The excess ROS in the cells lead to the injury-induced modification of important macromolecules in the cell, lipid peroxidation leads to changes in membrane structure and function, oxidation of proteins mercapto and amidogen lead to a loss of activity of important enzymes, and DNA injury leads to cell mutation $(7,8)$. The present study demonstrated that treatment with 50 and $100 \mathrm{mg} / \mathrm{kg}$ hesperidin significantly inhibited the activity of MDA, and increased the activities of SOD and
CAT in AMI mice. Zhang et al reported that hesperidin also inhibited oxidative stress in isoniazid- and rifampicin-induced liver injury in rats (26).

Cell apoptosis is an essential biological activity (27). It is an organic component essential for human and animal survival (27), and is a normal physiological process. If the transmission signal pathway regulating cell apoptosis is seriously damaged, it can lead to a series of human diseases, including cancer, and various types of infectious diseases (28). Bcl-2 family members may directly induce cell apoptosis, thus being essential membrane protein molecules for cell apoptosis (28). In addition, cell apoptosis can be controlled through different intracellular and extracellular signals. It has been detected that certain genes can promote apoptotic cytokines, 

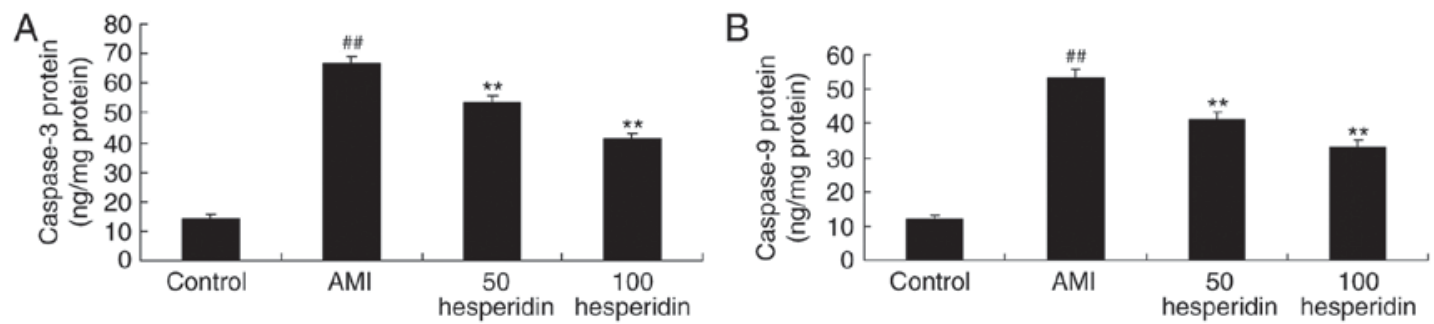

Figure 7. Preventive effect of hesperidin on caspase- 3 and caspase-9 in AMI mice. Preventive effect of hesperidin on (A) caspase-3 and (B) caspase-9 in AMI mice. ${ }^{\# \#} \mathrm{P}<0.01$, compared with control group; ${ }^{* *} \mathrm{P}<0.01$, compared with AMI model mice group. AMI, acute myocardial infarction; Control, control group; 50 hesperidin, $50 \mathrm{mg} / \mathrm{kg}$ hesperidin-treated group; 100 hesperidin, $100 \mathrm{mg} / \mathrm{kg}$ hesperidin-treated group.
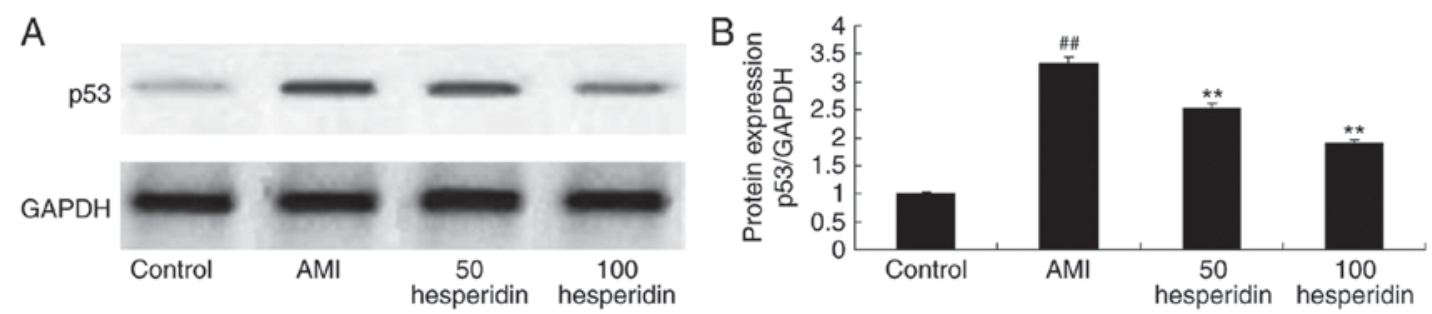

Figure 8. Preventive effect of hesperidin on the protein expression of p53 in AMI mice. Preventive effect of hesperidin on the protein expression of p53, determined using (A) western blot analysis and (B) statistical analysis. ${ }^{\# \#} \mathrm{P}<0.01$, compared with control group; ${ }^{* *} \mathrm{P}<0.01$, compared with AMI model mice group. AMI, acute myocardial infarction; Control, control group; 50 hesperidin, $50 \mathrm{mg} / \mathrm{kg}$ hesperidin-treated group; $100 \mathrm{hesperidin,} 100 \mathrm{mg} / \mathrm{kg}$ hesperidin-treated group.
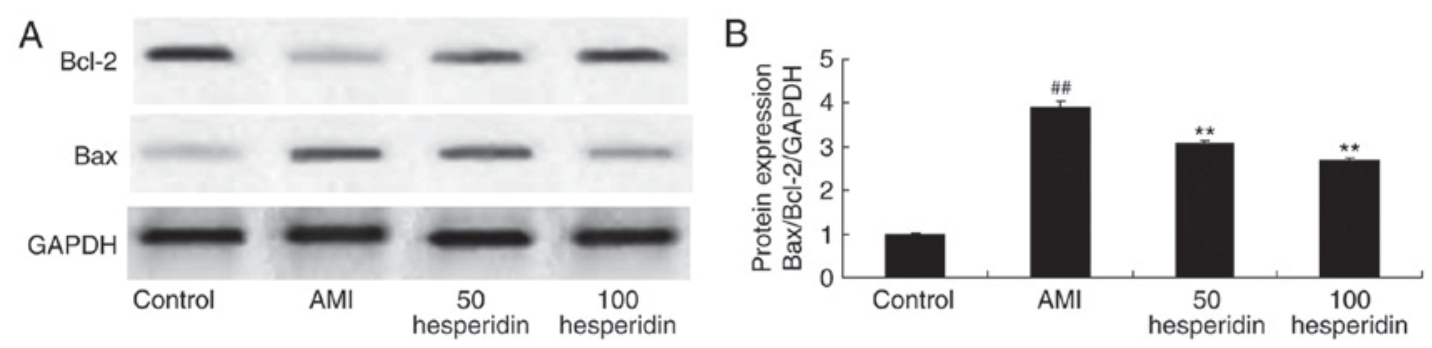

Figure 9. Preventive effect of hesperidin on the protein expression of Bax/Bcl-2 of in AMI mice. Preventive effect of hesperidin on the protein expression of Bax/Bcl-2, using (A) western blot analysis with (B) statistical analysis. ${ }^{\# \#} \mathrm{P}<0.01$, compared with control group; ${ }^{* *} \mathrm{P}<0.01$, compared with AMI model mice group. AMI, acute myocardial infarction; Control, control group; 50 hesperidin, $50 \mathrm{mg} / \mathrm{kg}$ hesperidin-treated group; 100 hesperidin, $100 \mathrm{mg} / \mathrm{kg}$ hesperidin-treated group; Bcl-2, B-cell lymphoma 2; Bax, Bcl-2-associated X protein.
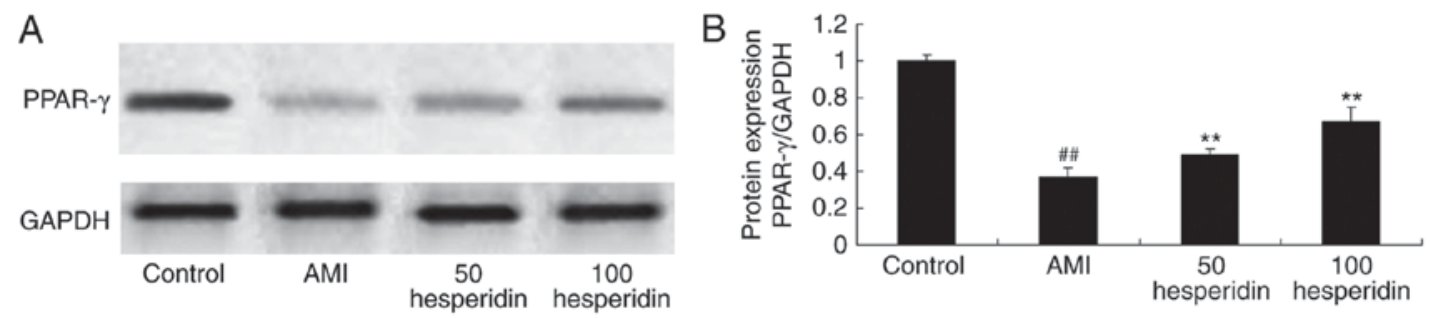

Figure 10. Preventive effect of hesperidin on the protein expression of PPAR- $\gamma$ in AMI mice hesperidin prevented the protein expression of PPAR- $\gamma$, determined using (A) western blot analysis and (B) statistical analysis. ${ }^{\# \#} \mathrm{P}<0.01$, compared with control group; *"P $<0.01$, compared with AMI model mice group. AMI, acute myocardial infarction; Control, control group; AMI, AMI model mice group; 50 hesperidin, $50 \mathrm{mg} / \mathrm{kg}$ hesperidin-treated group; 100 hesperidin, $100 \mathrm{mg} / \mathrm{kg}$ hesperidin-treated group; PPAR- $\gamma$, peroxisome proliferator-activated receptor- $\gamma$.

including Bax, P53 and Fas, and certain genes can inhibit apoptotic cytokines (14). The initiation and inhibition of apoptotic proteins is decisive of the cell apoptotic ratio in the body (13). If the protein expression of $\mathrm{Bcl}-2$ is higher than that of Bax, it is conducive to the promoting cell survival. By contrast, it can accelerate cell apoptosis (13). Siddiqi et al suggested that hesperidin ameliorates trichloroethylene-induced nephrotoxicity through altering the expression of caspase-3, bax and bcl-2 in Wistar rats (29). The present study indicated that hesperidin significantly prevented the activities of caspase- 3 
and caspase-9, and suppressed the protein expression of $\mathrm{p} 53$ and Bax/Bcl-2 in AMI mice. Justin Thenmozhi et al demonstrated that hesperidin also ameliorates oxidative stress and apoptosis in Alzheimer's disease in rats (30).

PPAR- $\gamma$ is a ligand-activated transcription factor, which can regulate gene expression through the function of specific DNA reaction components (31). Its functions include transforming various homeostatic changes, medicinal or nutritive components, and various inflammatory stimuli into intracellular signals (31). It is an important messenger in regulating energy metabolism, cell differentiation, proliferation, apoptotic and inflammatory reactions, endogenous synthesis and the secretion of active materials (32). It was previously suggested that PPAR $-\gamma$ only existed in the differentiation of adipose cells, however, it has since been reported that PPAR- $\gamma$ exists extensively on a variety of cells, including myocardial cells, myocardial fibroblasts, mononuclear/macrophages and vascular smooth muscle cells (9). In addition to its involvement in adipose cell differentiation, PPAR- $\gamma$ also regulates gene transcription in the cardiovascular system, and the gene regulates lipogenesis and expression of the diabetes obesity gene (33). It is also involved in the transcriptional regulation of protein-coding genes, which are associated with a variety of physiological activities, including inflammatory reactions, immunoregulation, cell cycle regulation and tumor cell differentiation (33). PPAR- $\gamma$ exists on a variety of ligands and activators. Studies have shown that PPAR- $\gamma$ is important in resistance to ischemia-reperfusion injury, and is an important regulatory factor for cell inflammation and ischemia (11). In the present study, hesperidin significantly induced the protein expression of PPAR- $\gamma$ in AMI mice. Agrawal et al showed that hesperidin also exhibited cardioprotective effects in an ischemic heart disease model in diabetic rats through the PPAR- $\gamma$ pathway (34).

In conclusion, the present study confirmed that the preventive effect of hesperidin modulated AMI, inflammatory responses and antioxidant status in AMI mice through the expression of PPAR $-\gamma$ and Bcl-2. In this context, hesperidin may be clinically useful for the treatment of AMI.

\section{Acknowledgements}

This study was supported by the Natural Science Foundation of Guangdong Province (grant no. 9151802001000011).

\section{References}

1. Spatz ES, Beckman AL, Wang Y, Desai NR and Krumholz HM: Geographic variation in trends and disparities in acute myocardial infarction hospitalization and mortality by income levels, 1999-2013. JAMA Cardiol 1: 255-265, 2016.

2. Reinstadler SJ, Baum A, Rommel KP, Eitel C, Desch S, Mende M, Metzler B, Poess J, Thiele H and Eitel I: ST-segment depression resolution predicts infarct size and reperfusion injury in ST-elevation myocardial infarction. Heart 101: 1819-1825, 2015.

3. Pellaton C, Cayla G, Silvain J, Zeymer U, Cohen M, Goldstein P, Huber K, Pollack C Jr, Kerneis M, Collet JP, et al: Incidence and consequence of major bleeding in primary percutaneous intervention for ST-elevation myocardial infarction in the era of radial access: An analysis of the international randomized acute myocardial infarction treated with primary angioplasty and intravenous enoxaparin or unfractionated heparin to lower ischemic and bleeding events at short- and long-term follow-up trial. Am Heart J 170: 778-786, 2015.
4. Lemkes J, Nijveldt R, Beek AM, Knaapen P, Hirsch A, Meijers J, Allaart CP, van Rossum A and van Royen N: Evaluating the optimal timing of revascularisation in patients with transient ST-segment elevation myocardial infarction: Rationale and design of the TRANSIENT trial. J Cardiovasc Transl Res 7: 590-596, 2014.

5. Alestalo K, Miettinen JA, Vuolteenaho O, Huikuri $\mathrm{H}$ and Lehenkari P: Bone marrow mononuclear cell transplantation restores inflammatory balance of cytokines after ST segment elevation myocardial infarction. PLoS One 10: e0145094, 2015.

6. Aydin MU, Aygul N, Altunkeser BB, Unlu A and Taner A: Comparative effects of high-dose atorvastatin versus moderate-dose rosuvastatin on lipid parameters, oxidized-LDL and inflammatory markers in ST elevation myocardial infarction. Atherosclerosis 239: 439-443, 2015.

7. Bashar T and Akhter N: Study on oxidative stress and antioxidant level in patients of acute myocardial infarction before and after regular treatment. Bangladesh Med Res Counc Bull 40: 79-84, 2014.

8. Kitano D, Takayama T, Nagashima K, Akabane M, Okubo K, Hiro T and Hirayama A: A comparative study of time-specific oxidative stress after acute myocardial infarction in patients with and without diabetes mellitus. BMC Cardiovasc Disord 16: 102, 2016.

9. Ibarra-Lara Mde L, Sánchez-Aguilar M, Soria E, Torres-Narváez JC, Del Valle-Mondragón L, Cervantes-Pérez LG, Pérez-Severiano F, Ramírez-Ortega Mdel C, Pastelín-Hernández G, Oidor-Chan VH and Sánchez-Mendoza A: Peroxisome proliferator-activated receptors (PPAR) downregulate the expression of pro-inflammatory molecules in an experimental model of myocardial infarction. Can J Physiol Pharmacol 94: 634-642, 2016.

10. Lima Ede A, Lima MM, Marques CD, Duarte AL, Pita Ida R and Pita MG: Peroxisome proliferator-activated receptor agonists (PPARs): A promising prospect in the treatment of psoriasis and psoriatic arthritis. An Bras Dermatol 88: 1029-1035, 2013.

11. Lincoff AM, Tardif JC, Neal B, Nicholls SJ, Rydén L, Schwartz GG, Malmberg K, Buse JB, Henry RR, Wedel H, et al: Evaluation of the dual peroxisome proliferator-activated receptor $\alpha / \gamma$ agonist aleglitazar to reduce cardiovascular events in patients with acute coronary syndrome and type 2 diabetes mellitus: Rationale and design of the AleCardio trial. Am Heart J 166: 429-434, 2013.

12. Ata MA, Khand F, Shaikh SS and Ata MA: Effect of smoking on serum xanthine oxidase and malondialdehyde levels in patients with acute myocardial infarction. J Pak Med Assoc 65: 39-42, 2015.

13. Radhiga T, Rajamanickam C, Sundaresan A, Ezhumalai M and Pugalendi KV: Effect of ursolic acid treatment on apoptosis and DNA damage in isoproterenol-induced myocardial infarction. Biochimie 94: 1135-1142, 2012.

14. Jarr KU, Eschricht S, Burkly LC, Preusch M, Katus HA, Frey N and Chorianopoulos E: TNF-like weak inducer of apoptosis aggravates left ventricular dysfunction after myocardial infarction in mice. Mediators Inflamm 2014: 131950, 2014.

15. Zhang H, Wang Z, Feng SJ, Xu L, Shi HX, Chen LL, Yuan GD, Yan W, Zhuang W, Zhang YQ, et al: PEDF improves cardiac function in rats with acute myocardial infarction via inhibiting vascular permeability and cardiomyocyte apoptosis. Int J Mol Sci 16: 5618-5634, 2015.

16. Ning Y, Li Z and Qiu Z: FOXO1 silence aggravates oxidative stress-promoted apoptosis in cardiomyocytes by reducing autophagy. J Toxicol Sci 40: 637-645, 2015.

17. Hofma SH, Smits PC, Brouwer J, Velders MA, van't Hof AW, Queré M, de Vries CJ and van Boven AJ: Long-term follow-up of second-generation everolimus-eluting stents versus first-generation sirolimus-eluting stents in acute myocardial infarction: Three-year results of the XAMI trial. EuroIntervention 10: 1280-1283, 2015

18. Magro M, Raber L, Heg D, Taniwaki M, Kelbaek H, Ostojić M, Baumbach A, Tüller D, von Birgelen C, Roffi M, et al: The MI SYNTAX score for risk stratification in patients undergoing primary percutaneous coronary intervention for treatment of acute myocardial infarction: A substudy of the COMFORTABLE AMI trial. Int J Cardiol 175: 314-322, 2014.

19. Padilla S, Masiá M, García N, Jarrin I, Tormo C and Gutiérrez F: Early changes in inflammatory and pro-thrombotic biomarkers in patients initiating antiretroviral therapy with abacavir or tenofovir. BMC Infect Dis 11: 40, 2011. 
20. Ehrenpreis ED, Zhou Y, Alexoff A and Melitas C: Effect of the diagnosis of inflammatory bowel disease on risk-adjusted mortality in hospitalized patients with acute myocardial infarction, congestive heart failure and pneumonia. PLoS One 11: e0158926, 2016.

21. Toldo S, Marchetti C, Mauro AG, Chojnacki J, Mezzaroma E, Carbone S, Zhang S, Van Tassell B, Salloum FN and Abbate A: Inhibition of the NLRP3 inflammasome limits the inflammatory injury following myocardial ischemia-reperfusion in the mouse. Int J Cardiol 209: 215-220, 2016.

22. Prondzinsky R, Unverzagt S, Lemm H, Wegener N, Heinroth K Buerke U, Fiedler M, Thiery J, Haerting J, Werdan $K$ and Buerke M: Acute myocardial infarction and cardiogenic shock: Prognostic impact of cytokines: INF- $\gamma$, TNF- $\alpha$, MIP-1 $\beta$, G-CSF, and MCP-1 $\beta$. Med Klin Intensivmed Notfmed 107: 476-484, 2012

23. Davies NM, Smith GD, Windmeijer F and Martin RM: COX-2 selective nonsteroidal anti-inflammatory drugs and risk of gastrointestinal tract complications and myocardial infarction: An instrumental variable analysis. Epidemiology 24: 352-362, 2013.

24. Rotimi SO, Bankole GE, Adelani IB and Rotimi OA: Hesperidin prevents lipopolysaccharide-induced endotoxicity in rats. Immunopharmacol Immunotoxicol 38: 364-371, 2016.

25. Stamboul K, Lorin J, Lorgis L, Guenancia C, Beer JC, Touzery C, Rochette L, Vergely C, Cottin Y and Zeller M: Atrial fibrillation is associated with a marker of endothelial function and oxidative stress in patients with acute myocardial infarction. PLoS One 10: e0131439, 2015.

26. Zhang G, Zhu J, Zhou Y, Wei Y, Xi L, Qin H, Rao Z, Han M, $\mathrm{Ma} \mathrm{Y}$ and $\mathrm{Wu} \mathrm{X}$ : Hesperidin alleviates oxidative stress and upregulates the multidrug resistance protein 2 in isoniazid and rifampicin-induced liver injury in rats. J Biochem Mol Toxicol 30: 342-349, 2016.

27. Aonuma T, Takehara N, Maruyama K, Kabara M, Matsuki M, Yamauchi A, Kawabe J and Hasebe N: Apoptosis-resistant cardiac progenitor cells modified with apurinic/apyrimidinic endonuclease/redox factor 1 gene overexpression regulate cardiac repair after myocardial infarction. Stem Cells Transl Med 5: 1067-1078, 2016.
28. Tseng CY, Wang JS, Chang YJ, Chang JF and Chao MW: Exposure to high-dose diesel exhaust particles induces intracellular oxidative stress and causes endothelial apoptosis in cultured in vitro capillary tube cells. Cardiovasc Toxicol 15: 345-354, 2015.

29. Siddiqi A, Nafees S, Rashid S, Sultana S and Saidullah B: Hesperidin ameliorates trichloroethylene-induced nephrotoxicity by abrogation of oxidative stress and apoptosis in wistar rats. Mol Cell Biochem 406: 9-20, 2015.

30. Justin Thenmozhi A, William Raja TR, Manivasagam T, Janakiraman U and Mohamed Essa M: Hesperidin ameliorates cognitive dysfunction, oxidative stress and apoptosis against aluminium chloride induced rat model of Alzheimer's disease. Nutr Neurosci 20: 360-368, 2017.

31. Yu Y, Zhang ZH, Wei SG, Weiss RM and Felder RB: Peroxisome proliferator-activated receptor- $\gamma$ regulates inflammation and renin-angiotensin system activity in the hypothalamic paraventricular nucleus and ameliorates peripheral manifestations of heart failure. Hypertension 59: 477-484, 2012.

32. Yasuda S, Kobayashi H, Iwasa M, Kawamura I, Sumi S, Narentuoya B, Yamaki T, Ushikoshi H, Nishigaki K, Nagashima K, et al: Antidiabetic drug pioglitazone protects the heart via activation of PPAR-gamma receptors, PI3-kinase, Akt, and eNOS pathway in a rabbit model of myocardial infarction. Am J Physiol Heart Circ Physiol 296: H1558-H1565, 2009.

33. Kuo MY, Ou HC, Lee WJ, Kuo WW, Hwang LL, Song TY, Huang CY, Chiu TH, Tsai KL, Tsai CS and Sheu WH: Ellagic acid inhibits oxidized low-density lipoprotein (OxLDL)-induced metalloproteinase (MMP) expression by modulating the protein kinase $\mathrm{C}$ - $\alpha /$ extracellular signal-regulated kinase/peroxisome proliferator-activated receptor $\gamma /$ nuclear factor- $\kappa \mathrm{B}(\mathrm{PKC}-\alpha / \mathrm{ERK} / \mathrm{PPAR}-\gamma / \mathrm{NF}-\kappa \mathrm{B})$ signaling pathway in endothelial cells. J Agric Food Chem 59: 5100-5108, 2011.

34. Agrawal YO, Sharma PK, Shrivastava B, Ojha S, Upadhya HM, Arya DS and Goyal SN: Hesperidin produces cardioprotective activity via PPAR- $\gamma$ pathway in ischemic heart disease model in diabetic rats. PLoS One 9: e111212, 2014. 